\title{
Estimating the welfare gains from public schools in rural India
}

\author{
Debopam Bhattacharya* $^{*} \quad$ Anders Kjelsrud $^{\dagger} \quad$ Rohini Somanathan ${ }^{\ddagger}$
}

June, 2019

\begin{abstract}
We adapt recently developed econometric techniques to estimate the distribution of welfare gains from public schools in rural India. Individuals have preferences over school quality and income spent on other goods. In a situation where both private and pubic schools are available, we define the cash-equivalent value of the public school as the hypothetical income sacrifice that would equate an individual's utility to his/her utility when only the private school was available. We apply this procedure to data on income, enrollment and school quality from the Indian Human Development Survey of 2012 and estimate the distribution of implicit transfers across states and income deciles. We find these transfers are progressive. Poor households receive more on average because they have higher fertility and because their children are more likely to attend state schools. We also find however that transfers are particularly small for some of the poorest states in central and eastern India because of their low public school quality. Our methods can be generalized to measure the distribution of benefits from other types of public goods and government services.
\end{abstract}

\footnotetext{
*University of Cambridge (db692@cam.ac.uk)

${ }^{\dagger}$ University of Oslo (a.g.kjelsrud@econ.uio.no)

${ }^{\ddagger}$ Delhi School of Economics (rohini@econdse.org)
} 


\section{Introduction}

In many poor and middle income countries, both public and private institutions are significant players in the provision of basic education. Despite constitutional commitments to free universal basic education, well-functioning public schools are not accessible in many Indian villages and about one-fifth of primary school children attend private schools. ${ }^{1}$ In this paper, we adapt recently developed econometric techniques to estimate the distribution of welfare gains from public schools in rural India.

Estimating the benefits from public services is desirable for at least two distinct reasons. First, to assess the degree of targeting in public expenditures. If facilities of comparable quality do not exist everywhere, their location and the composition of their users will determine whether public spending is progressive. Second, to properly measure poverty and income inequality in a society. Consider two otherwise identical households, one of which can easily access a free public school while the other is forced to rely on a private school of similar quality. The consumption of the first household will be underestimated if we do not account for the value of education services it receives. The implications of these omissions can be far-reaching because eligibility for many government welfare schemes depend on a household's measured poverty and grants from the central to state governments depend on the poverty counts.

There have been several attempts to estimate the welfare effects of public services. One important approach has been to use costs of provision as a measure of benefit incidence. ${ }^{2}$ This is especially problematic in countries such as India, where high public salaries, teacher absenteeism and low public school quality move together (Kremer et al., 2005). We provide an alternative approach to estimating welfare changes from public services using the concept of cash-equivalence from the welfare economics toolkit. We ask what hypothetical income sacrifice in the situation where both the private and the state schools are available, would equate an individual's utility from attending the state school to that from attending a private school when only the latter is available. Our

\footnotetext{
${ }^{1}$ See Kingdon (2017). Estimates of the share of children attending private schools vary across data sets because of differences in sampling frames, in the definition of "private" and in the age-group considered. Most estimates for rural India lie in the 20-30 per cent range.

${ }^{2}$ For example, Chapters 7 and 8 in Van de Walle et al. (1995) use this approach to examine the distribution of benefits from public education in Peru and Pakistan respectively.
} 
methods are based on Bhattacharya (2018), adapted to the school choice scenario.

We then apply these methods to household data on income and enrollment from the Indian Human Development Survey (IHDS) of 2012 to estimate cash-equivalent welfare gains by income deciles. The IHDS is a nationally representative survey, and we choose this instead of the much larger National Sample Surveys (NSS) because the IHDS has data on income, which is a major determinant of a household's choice between public and private schools. It also includes schooling costs at the child level and reports scores for tests of reading, writing and math, which we use as a proxy for school quality.

We find that the distribution of gains from public schooling is progressive, in that poorer income deciles gain the most from these schools. State schooling therefore reduces income inequality. This pattern is especially marked when income deciles are defined within each state. Poor households gain more because of their greater propensity to send their children to public schools, and also because they have higher average fertility rates. The effect on overall, country-level income inequality is somewhat weakened by the fact that transfers are larger in richer states due to their better performing public school systems.

The rest of the paper proceeds as follows. Section 2 outlines our methods. Section 3 describes the data used. Results are in Section 4 and some robustness analysis in Section 5. Brief concluding remarks are in Section 6.

\section{Methods and formulae}

Consider a setting of binary choice between a private school versus a state school, denoted by 1 and 0 , respectively. Both these are available at a given set of qualities and costs. To estimate the welfare effect of having a state-school we use the cash-equivalent, defined as the hypothetical income sacrifice that would equate an individual's utility from state school to that of the private school when only the latter is available. Applied researchers typically use the heuristic idea that introducing an alternative is "like" lowering its price to minus infinity, and thereafter use the welfare formulae for price change to evaluate welfare effects of adding an alternative. Our analysis below provides a formal justification for this heuristic approach. 
The specific set-up is as follows. Suppose all kids go to school. The prices of state and private schools in a particular environment are denoted by $p_{0}, p_{1}$, individual income is denoted by $y$, the qualities of the state and private schools are $x_{0}$ and $x_{1}$ respectively. Individual utilities are $U_{1}\left(y-p_{1}, x_{1}, \eta\right)$ if private and $U_{0}\left(y-p_{0}, x_{0}, \eta\right)$ if state. $U_{1}$ and $U_{0}$ can be the same function or not; it does not matter for the calculations. The random vector $\eta$ represents unobserved heterogeneity in preferences. Utilities are strictly increasing in the first two arguments, and no assumption is imposed on the dimension of $\eta$ or how it affects preferences. We assume that for any $x$ and $\eta$, the function $U_{j}(\cdot, x, \eta)$ is strictly increasing and continuous, and $U_{j}(\infty, x, \eta)=\infty$ and $U_{j}(-\infty, x, \eta)=-\infty$, for $j=0,1$.

Let $q_{1}\left(p_{0}, p_{1}, x_{0}, x_{1}, y\right)$ denote the fraction of kids at income $y$ and facing price $p_{0}, p_{1}$ and qualities $x_{0}, x_{1}$ who would choose the private option.

$$
q_{1}\left(p_{0}, p_{1}, x_{0}, x_{1}, y\right)=\operatorname{Pr}\left(U_{1}\left(y-p_{1}, x_{1}, \eta\right) \geq U_{0}\left(y-p_{0}, x_{0}, \eta\right)\right),
$$

and $q_{0}\left(p_{0}, p_{1}, x_{0}, x_{1}, y\right)=1-q_{1}\left(p_{0}, p_{1}, x_{0}, x_{1}, y\right)$ denote state-school attendance.

We see below that if income and the prices of both schools change by the same amount, no individual's demand can change and so aggregated choice remains unchanged. In particular, for any $b$, we have:

$$
\begin{aligned}
& q_{1}\left(p_{0}+b, p_{1}+b, x_{0}, x_{1}, y+b\right) \\
& =\operatorname{Pr}\left(U_{1}\left(y+b-\left(p_{1}+b\right), x_{1}, \eta\right) \geq U_{0}\left(y+b-\left(p_{0}+b\right), x_{0}, \eta\right)\right) \\
& =\operatorname{Pr}\left(U_{1}\left(y-p_{1}, x_{1}, \eta\right) \geq U_{0}\left(y-p_{0}, x_{0}, \eta\right)\right) \\
& =q_{1}\left(p_{0}, p_{1}, x_{0}, x_{1}, y\right) .
\end{aligned}
$$

This fact will be used below. This is analogous to demand in the standard continuous case being homogenous of degree zero in prices and income.

Then the cash-equivalent of state school provision at $\left(p_{0}, x_{0}\right)$ is defined as the hypothetical income sacrifice in the situation where both the private and the state schools are available that equates an individual's utility to that obtained when only a private option is available. Formally, the individual cash-equivalent is the solution $S$ to the equation

$$
\begin{aligned}
& \max \left\{U_{0}\left(y-S-p_{0}, x_{0}, \eta\right), U_{1}\left(y-S-p_{1}, x_{1}, \eta\right)\right\} \\
& =U_{1}\left(y-p_{1}, x_{1}, \eta\right)
\end{aligned}
$$


The existence and uniqueness of $S$ follows from the assumptions on $U_{0}\left(\cdot, x_{0}, \eta\right)$ and $U_{1}\left(\cdot, x_{1}, \eta\right)$. Since $S$ depends on the unobserved $\eta$, there is random variation in $S$. We want to know the distribution, i.e. $\mathrm{CDF}$ and hence mean, median etc. of $S$.

Toward that end, observe that $\operatorname{Pr}[S<0]=0$, since LHS of $(3)$ will be at least $U_{1}\left(y-S-p_{1}, x_{1}, \eta\right)$ which will exceed the RHS. Next,

$$
\begin{aligned}
\operatorname{Pr}(S=0) & =\operatorname{Pr}\left(U_{1}\left(y-p_{1}, x_{1}, \eta\right) \geq U_{0}\left(y-p_{0}, x_{0}, \eta\right)\right) \\
& =q_{1}\left(p_{0}, p_{1}, x_{0}, x_{1}, y\right)
\end{aligned}
$$

For $a>0$, since LHS of (3) is strictly decreasing in $S$, we have that

$$
\begin{aligned}
\operatorname{Pr}(S \leq a) & =\operatorname{Pr}\left[\begin{array}{c}
\max \left\{U_{0}\left(y-a-p_{0}, x_{0}, \eta\right), U_{1}\left(y-a-p_{1}, x_{1}, \eta\right)\right\} \\
\leq U_{1}\left(y-p_{1}, x_{1}, \eta\right)
\end{array}\right] \\
& =\operatorname{Pr}\left[U_{0}\left(y-a-p_{0}, x_{0}, \eta\right) \leq U_{1}\left(y-p_{1}, x_{1}, \eta\right)\right] \\
& =q_{1}\left(p_{0}, p_{1}-a, x_{0}, x_{1}, y-a\right) \\
& =q_{1}\left(p_{0}+a, p_{1}, x_{0}, x_{1}, y\right)
\end{aligned}
$$

Therefore mean welfare is (N.B. for a nonnegative random variable $S$ with $\operatorname{CDF} F(\cdot), E(S)=$ $\left.\int_{0}^{\infty}(1-F(s)) d s\right)$ :

$$
\begin{aligned}
E(S) & =\int_{0}^{\infty}\left[1-q_{1}\left(p_{0}+a, p_{1}, x_{0}, x_{1}, y\right)\right] d a \\
& =\int_{0}^{\infty} q_{0}\left(p_{0}+a, p_{1}, x_{0}, x_{1}, y\right) d a \\
& =\int_{0}^{\infty} q_{0}\left(p_{0}, p_{1}-a, x_{0}, x_{1}, y-a\right) d a
\end{aligned}
$$

where the last equality follows from (2) with $b=-a$.

Corollary 1 If the state school is free, and the private school costs $p$, then the above formula becomes

$$
\int_{0}^{\infty} \tilde{q}_{0}\left(p-r, x_{0}, x_{1}, y-r\right) d r
$$

where $\tilde{q}_{0}\left(p, x_{0}, x_{1}, y\right)$ denotes the probability of choosing the free state-school when price of the private school is $p$, qualities are $x_{0}, x_{1}$ and income is $y$, as above.

The results stated above are fully nonparametric, and do not require specification of the utility functions or the distribution of unobserved heterogeneity. However, for ease of computation with 
moderately sized datasets, we use parametric models for computation. In particular, to apply the above formulae to the data, we use a probit model to estimate the $q_{0}(\cdot)$ function on observations where the prices, quality and household income are either directly observed or indirectly imputed. The integral in (6) is computed numerically, using STATA's in-built "integ" command that uses a variant of the Trapeziodal rule.

The choice of the upper limit of the integral does affect our results. We take the view that the upper limit of the integral is really the price of the state school where demand for it equals zero (since demand cannot be negative in our context). It is difficult to observe this extreme price in the data, so we report the results from different choices of this upper limit. In our baseline estimates we use the 99th percentile of the distribution of state school prices within each Indian state.

We calculate (6) for each state and income decile separately to get cash-equivalents for each decile within a state. When computing the total benefit at the household level, we allocate the cashequivalents to households based on their location in the income distribution. Since the cashequivalents are defined per child aged 5 to 11, we multiply by the number of children in this age group to arrive at the total transfer for each household.

\section{Data}

For data on income, school quality and prices, we use the Indian Human Development Survey (IHDS) from 2011-12 (Desai et al., 2015). The IHDS is unusual among nationally representative household surveys in India because it records school enrollment choices and costs for each child and also household income in addition to aggregate household consumption. These variables are essential in order to estimate the demand function for schooling on which our computations are based. Income data also allows us to analyse the effects of our cash-equivalent transfers on income inequality.

We measure the cost of schooling for each household as the sum of tuition fees and expenditure on materials, such as books and uniforms. We then calculate school prices as the median cost within each village, separately for state and private schools. ${ }^{3}$ Household income is constructed

\footnotetext{
${ }^{3}$ The price calculations are based on an average of 9 and 6.6 students per village for state and private schools
} 
from responses to questions on roughly 50 different income sources, including wages, farm and business income, property income, remittances, pensions and other transfers.

To measure school quality, we use achievement tests conducted as part of the IHDS. These tests are conducted in reading, writing and math for children aged 8 to 11 years. These tests are similar to those used in the widely cited Annual Status of Education Report (ASER). A child's score is determined by the highest level they are able to complete. The reading test in the IHDS has five scores (0: can not read, 1: letter, 2: word, 3: paragraph and 4: story), while the math test has four scores (0: can not recognise numbers, 1: numbers, 2: subtraction, 3: division). The writing test is based on writing a short text and has three scores (0: can not write, 1: writes with 2 or less mistakes, 2: writes with no mistake). We simply add these scores to construct an overall quality index (with a maximum value of 9). As with school costs, we use the village median of this index for each type of school as our measure of quality.

We prefer to use these test scores to other school characteristics such as per pupil expenditures or teacher qualifications that have sometimes been used in the literature to proxy for school quality. State expenditures on public schools overstate the value of state schooling in India because of high public sector salaries, teacher absenteeism and other types of inefficiencies (Kingdon and Teal, 2010; Kjelsrud and Somanathan, 2017b; Kremer et al., 2005). Also, what is relevant for our purposes is perceived quality and one can reasonably argue that student achievement is the most easily available marker of quality available to parents who are making choices between public and private alternatives.

We exclude small states and union territories because of our small sample size for these areas. We also limit ourselves to rural households. There is a range of schooling options in urban areas with varying prices and qualities. The median costs and qualities we use to estimate the demand for public schools schooling are therefore less meaningful.

Of roughly 26,000 rural households in the survey, there are 11,000 with a total of 18,000 primary school aged children. ${ }^{4}$ Our demand function for state schools is estimated using a sample that is respectively. We have fewer observations for quality ( and average of 4.5 students for state schools 3.1 students for private schools) because the test was only administered to children above 8 whereas costs are available for all primary school children. Religious schools are placed in the private school category.

${ }^{4}$ This is after we remove households with zero or negative income. This reduces the number of household by 1.8 
further restricted as follows. We exclude villages which do not have students in both state and private schools and also those children for which we have no information on test scores and costs. This brings the sample size down to about 10,200 children. We also exclude children that are out of school. This reduces our sample to 9,118 children from 5,357 households. Table 1 provides summary statistics for the different samples. Families with children in the age group 5 to 11 have lower average income than other families (Column 2 versus Column 1). Average income in the estimation sample is comparable to the full sample of families with young children (Column 3 versus Column 2). Private school attendance is higher because we restrict ourselves to villages for which private and public school attendance are both positive.

Table 2 has summary statistics for school prices and quality, as well as the other variables used in our regression. The average monthly price of private schools is about 380 rupees, whereas the average for state schools is 45 rupees. Not surprisingly, parents of children in private schools are, on average, more educated and more affluent. They are also more likely to be male. We see that private schools have higher test scores. This reflects both quality and sorting across the two types of schools based on unobservable household and child characteristics. While our theoretical framework controls for this unobserved heterogeneity, our data does not allow this since we observe each child only in a single school environment.

\section{Results}

Table 3 presents estimates from the probit model, displayed as marginal effects evaluated at the mean values of our explanatory variables. Controls include the age and gender of the child and parent education. Standard errors are clustered at the village level. Coefficients have expected signs. A 10 percent increase in per capita income is estimated to decrease the likelihood of attending a state school by 1.2 percentage points and a price increase of 100 rupees for the state school (a little less than two standard deviations, see Table 2) reduces the likelihood of attendance by 4.1 percentage points, while a one unit increase in achievement scores in state schools increases attendance by 1.6 percentage points.

In Table 4 we present estimates of cash-equivalent values of public schooling for each of the Indian percent. Negative values are most commonly reported for farm income. 
TABLE 1: Sample sizes and key statistics

\begin{tabular}{lccc}
\hline \hline & Full & HHs with & Estimation \\
& sample & children $5-11$ & sample \\
& $(1)$ & $(2)$ & $(3)$ \\
\hline Households & & & \\
Monthly income per capita & 1686 & 1198 & 1255 \\
Number of HHs & 26211 & 10838 & 5357 \\
Number of villages & 1,376 & 1,351 & 586 \\
Number of children (5-11) & 17889 & 17889 & 9118 \\
& & & \\
Children aged 5-11 (shares) & & & 57.8 \\
Enrolled in state school & & 24.2 & 38.8 \\
Enrolled in private school & & 2.1 & 3.4 \\
Enrolled in other school & & 13.5 & - \\
Not enrolled in school & & & \\
\hline \hline
\end{tabular}

TABle 2: Summary statistics, estimation sample

\begin{tabular}{lcrrr}
\hline \hline & \multicolumn{2}{c}{ State schools } & \multicolumn{2}{r}{ Private schools } \\
& Mean & SD & Mean & SD \\
& $(1)$ & $(2)$ & $(3)$ & $(4)$ \\
\hline School price (Rs. per month) & 44.71 & $(57.17)$ & 364.77 & $(355.07)$ \\
School quality (Avg. test score) & 4.51 & $(2.27)$ & 5.98 & $(2.10)$ \\
Log per capita income & 6.62 & $(0.85)$ & 7.03 & $(1.02)$ \\
Age of child & 8.28 & $(1.87)$ & 8.04 & $(1.94)$ \\
Female & 0.52 & $(0.50)$ & 0.40 & $(0.49)$ \\
Max years of schooling of parents & 4.47 & $(4.28)$ & 6.13 & $(4.89)$ \\
Number of children & 5268 & & 3850 & \\
\hline \hline
\end{tabular}

Note: The school prices are in rupees per month, while the school quality index is based on the IHDS test scores. 
TABle 3: Probit model: State school attendance

\begin{tabular}{lc}
\hline \hline Log per capita income & $\begin{array}{c}-0.12094^{* * *} \\
(0.01021)\end{array}$ \\
Price state school & $-0.00041^{* *}$ \\
& $(0.00019)$ \\
Price private school & $0.00017^{* * *}$ \\
& $(0.00004)$ \\
Quality state school & $0.01622^{* * *}$ \\
& $(0.00574)$ \\
Quality private school & -0.00052 \\
& $(0.00580)$ \\
\hline$N$ & 9118 \\
$R^{2}$ & 0.0732 \\
\hline \hline
\end{tabular}

Note: ${ }^{*} p<0.1,{ }^{* *} p<0.05,{ }^{* * *} p<0.01$.

Robust standard errors clustered at the village level are shown in the parentheses.

Controls include age and gender dummies and the maximum years of schooling of parents. 
states based on the methods outlined in Section 2. All estimates are per child in the age group 5 to 11 years and in monthly rupee values. The first column shows average cash-equivalent values by states. We interpret this as the average value placed on a public school in that state. The last row labelled "All-India", presents the corresponding estimate using a pooled sample of all states. Column (2) to Column (4) provide estimates of cash-equivalents for the 1st, 5th and 10th decile in each state.

Overall transfers depend on both the quality of state schools and the fraction of the population that uses them. Interesting cross-state patterns in the level of transfers and their redistributive effects are seen in Figures 1 and 2. In Figure 1 we plot rural poverty rates versus cash-equivalents for the poorest decile. The figure shows that poor households in states with relatively low levels of poverty, such as Kerala, Tamil Nadu and Jammu and Kashmir, have much higher cash-equivalents than equally households in states with high levels of poverty, such as Jharkhand and Chhattishgarh. ${ }^{5}$

All estimates thus far have been per child, ignoring differences in the number of children across states and across income groups. In Figure 2 we present the overall distributional impact of state schooling, by plotting the shares of total cash-equivalents accrued by different income groups. Since income is at the household level, this incorporates the effects of household size, giving higher transfers to households with more primary-aged children. The bars in the figure show shares of total benefits by within-state income deciles. On average, poor households have more such children and therefore receive much higher benefits. The poorest decile gains about five times the amount of the richest decile. State schooling appears highly progressive. The dots in the figure show shares of cash-equivalents by deciles from the overall income distribution. These transfers are also progressive but less so than those within states, because poorer states also have weaker public school systems.

\footnotetext{
${ }^{5}$ This increase in the variance of poverty rates across states is consistent with findings in Kjelsrud and Somanathan (2017a).
} 
TABLE 4: Monthly cash-equivalents per child, by state and income group

\begin{tabular}{lrrrr}
\hline \hline & Average & Decile 1 & Decile 5 & Decile 10 \\
& $(1)$ & $(2)$ & $(3)$ & $(4)$ \\
\hline Andhra Pradesh & 145 & 194 & 147 & 82 \\
Assam & 358 & 382 & 346 & 118 \\
Bihar & 129 & 162 & 139 & 65 \\
Chhattisgarh & 99 & 122 & 102 & 51 \\
Gujarat & 153 & 230 & 155 & 54 \\
Haryana & 340 & 463 & 336 & 165 \\
Himachal Pradesh & 175 & 239 & 163 & 86 \\
Jammu and Kashmir & 313 & 486 & 349 & 177 \\
Jharkhand & 120 & 173 & 127 & 66 \\
Karnataka & 172 & 214 & 179 & 96 \\
Kerala & 183 & 294 & 207 & 62 \\
Madhya Pradesh & 64 & 84 & 69 & 40 \\
Maharashtra & 178 & 245 & 191 & 104 \\
Odisha & 99 & 126 & 107 & 63 \\
Punjab & 265 & 342 & 289 & 139 \\
Rajasthan & 261 & 374 & 267 & 141 \\
Tamil Nadu & 309 & 452 & 297 & 215 \\
Uttar Pradesh & 109 & 141 & 115 & 56 \\
Uttarakhand & 147 & 207 & 148 & 86 \\
West Bengal & 127 & 162 & 136 & 74 \\
\hline All-India & 196 & - & - & - \\
\hline \hline
\end{tabular}

Note: Column (1) presents average cash-equivalents, while Column (2) to (4) present average cash-equivalents by within-state deciles. 
FiguRE 1: Poverty rates versus cash-equivalents

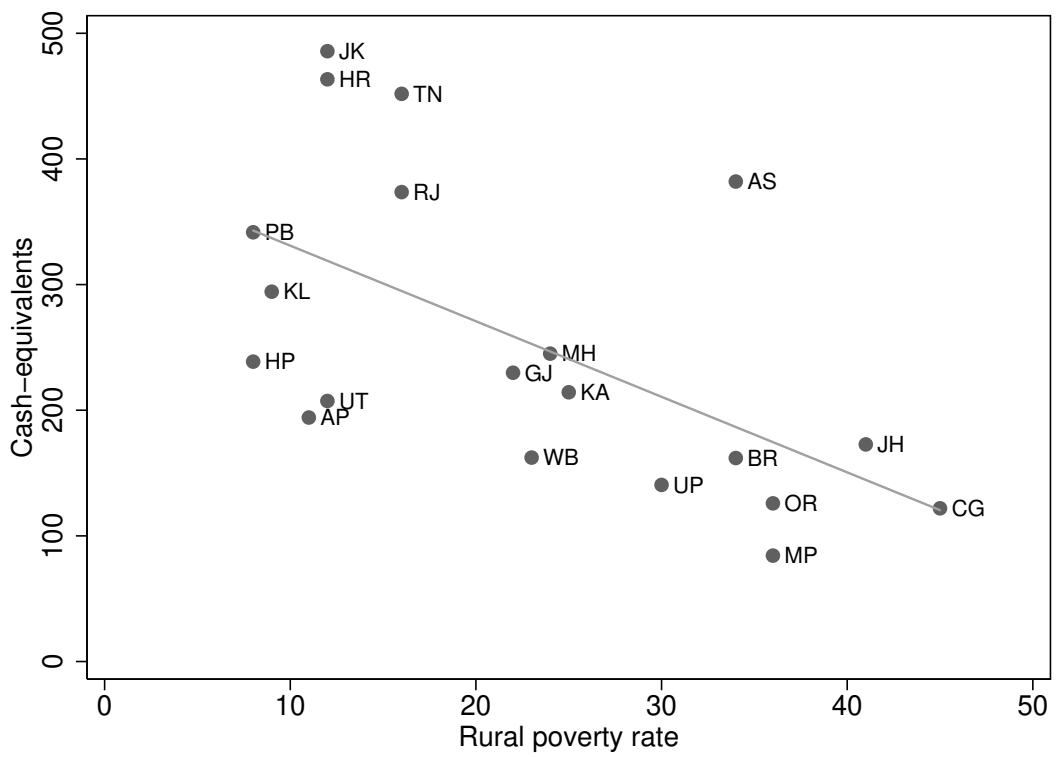

Note: The horizontal axes shows rural poverty rates, as they appear in Government of India (2013).

The vertical axes shows average cash-equivalents for the poorest income decile in each state.

Figure 2: Share of cash-equivalents by within-state and overall income deciles

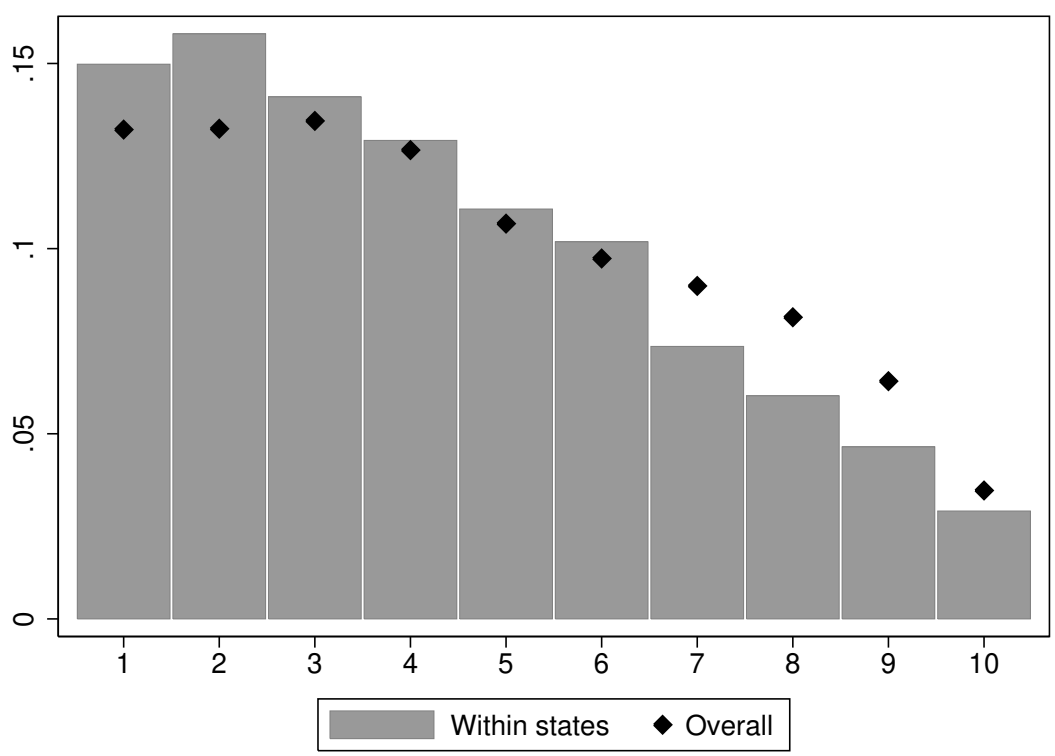

Note: The figure shows the share of total cash-equivalents accrued by different deciles. "Within states" shows average values based on within state deciles, while "Overall" shows averages based on overall deciles. 


\section{Robustness}

Since our estimates of the cash-equivalent gains from public schooling are integrals of an estimated demand curve for state schools, they are sensitive to the limits of integration. Our estimates thus far use the 99th percentile of the distribution of public school prices within each state as an upper limit of the integral in (6). In this section we show estimates using the 90th and 95th percentile of the distribution of prices. We also calculate the ratio of state to private school prices for each village and identify the highest such ratio within states. For each village, we then integrate up to the point where the state school price, relative to the local private school price, reaches this highest observed ratio. We compute the distributions of gains from schooling across the income deciles for each of these three alternative limits.

The average cash-equivalent is, as expected, sensitive to the choice of upper limit. The average cash transfer varies from 37 rupees to 188 rupees, depending on which of the four upper limits we use. However, the distribution of transfers is very similar in all cases. We see this in Figure 3, which plots the share of total cash-equivalents received by within-state income deciles.

FiguRE 3: Share of cash-equivalents by within-state deciles, different upper limits

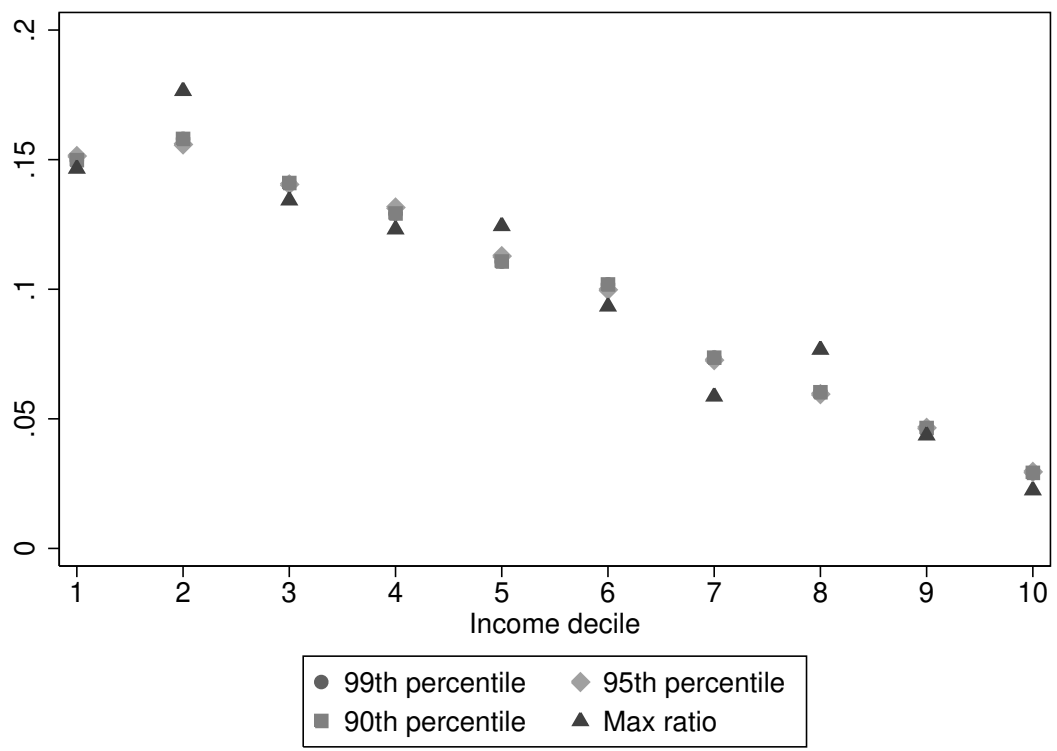

Note: The figure shows the share of total cash-equivalents accrued by within-state income deciles.

As a second robustness check we present alternative probit specifications. The estimates are shown in Table 5. Column (1) includes controls for state fixed-effects. Column (2) has per capita income 
replaced by income per consumer unit, using the OECD equivalence scale. This particular equivalence scale gives a weight of 1 to the first adult; 0.5 to the second and each subsequent person aged 14 and over; and 0.3 to each child aged under 14. Column (3) uses an alternative measure of school quality based on a principal component analysis of test scores rather than their sum. Our coefficients of interest are mostly unaffected by these alternative specifications.

TABLE 5: State school attendance, alternative specifications

\begin{tabular}{lccc}
\hline \hline & $\begin{array}{c}\text { State } \\
\text { fixed effects }\end{array}$ & $\begin{array}{c}\text { Equivalence } \\
\text { scaled income }\end{array}$ & $\begin{array}{c}\text { PCA } \\
\text { quality index }\end{array}$ \\
& $(1)$ & $(2)$ & $(3)$ \\
\hline Log per capita income $^{\dagger}$ & $-0.12774^{* * *}$ & $-0.12201^{* * *}$ & $-0.12097^{* * *}$ \\
& $(0.01044)$ & $(0.01038)$ & $(0.01021)$ \\
Price state school & $-0.00036^{* *}$ & $-0.00042^{* *}$ & $-0.00040^{* *}$ \\
& $(0.00016)$ & $(0.00019)$ & $(0.00019)$ \\
Price private school & $0.00012^{* * *}$ & $0.00017^{* * *}$ & $0.00017^{* * *}$ \\
& $(0.00003)$ & $(0.00004)$ & $(0.00004)$ \\
Quality state school & 0.00291 & $0.015767^{* * *}$ & $0.02794^{* * *}$ \\
& $(0.00545)$ & $(0.00573)$ & $(0.01080)$ \\
\hline$R^{2}$ & & & 0.00129 \\
\hline \hline
\end{tabular}

Note: ${ }^{*} p<0.1,{ }^{* *} p<0.05,{ }^{* * *} p<0.01$. Robust standard errors clustered at the village level are shown in the parentheses. All regressions include age dummies, a gender dummy and the maximum years of schooling of parents.

$\dagger$ Per consumer unit i Column (2). 


\section{Conclusion}

We see the contribution of this paper as two-fold. First, it provides a method for evaluating welfare benefits to households facing a binary choice between a publicly provided service and a private alternative. This approach could be systematically used to measure the value of transfers from all publicly provided services to arrive at augmented household income that better reflects the distribution of well-being than commonly used measures of consumption and income. It can also form the basis for a cost-benefit analysis of public provision. Second, the paper estimates the distribution of welfare gains from public schooling in India. We find that public schools, through available to all, are used disproportionately by the poor. This makes spending on primary schooling more progressive that many explicitly targeted programs.

\section{References}

Bhattacharya, D. (2018). Empirical welfare analysis for discrete choice: Some general results. Quantitative Economics, 9(2), 571-615.

Desai, S., Dubey, A., Joshi, B., Sen, M., Shariff, A., and Vanneman, R. (2015). India Human Development Survey (IHDS) - II. University of Maryland and National Council of Applied Economic Research, New Delhi [producers], Ann Arbor, MI: Inter-university Consortium for Political and Social Research [distributor].

Government of India (2013). Press Note on Poverty Estimates, 2011-12.

Kingdon, G. (2017). The private schooling phenomenon in India: A review.

Kingdon, G. and Teal, F. (2010). Teacher unions, teacher pay and student performance in India: A pupil fixed effects approach. Journal of Development Economics, 91(2), 278-288.

Kjelsrud, A. and Somanathan, R. (2017a). Incorporating public good availability into the measurement of poverty.

Kjelsrud, A. and Somanathan, R. (2017b). Poverty targeting through public goods. In A. Banerjee, P. Bardhan, R. Somanathan, and T. Srinivasan, editors, Poverty and Income Distribution in India. Juggernaut. 
Kremer, M., Chaudhury, N., Rogers, F. H., Muralidharan, K., and Hammer, J. (2005). Teacher absence in India: A snapshot. Journal of the European Economic Association, 3(2-3), 658-667.

Van de Walle, D., Nead, K., et al. (1995). Public spending and the poor: Theory and evidence. World Bank Publications. 